\title{
Note on the Liver Oil of the Tope. (Galeus galeus).
}

\section{By A. CHASTON CHAPMAN, Pres. I.C., F.R.S.}

In the course of the study of the chemistry of the liver oils of certain fish, I have had occasion to examine the oil from the liver of the tope. As I have not been able to find any reference to this oil in chemical literature, $I$ thought that it might be of interest to place some of my results on record.

For the following description of this fish I am indebted to Mr. C. Tate Regan, F.R.S.:-

The TOPE-Galeus galeus - is a widely distributed species: it occurs on all the coasts of the British Isles, but is much more abundant in England and Ireland than in Scotland. It belongs to the family Carchariidae-sharks without fin spines, with the first dorsal fin well in advance of the pelvis and with the last two or three gill slits above the base of the pectoral fin-and is distinguished from other forms with sharp-edged teeth by the possession of spiracles: in colour it is bluish-grey above and white beneath.

The tope usually attains a length of five or six feet, but specimens of seven feet long have been recorded. It swims low and feeds mainly at or near the bottom on fishes and other marine animals. In the summer, the adults approach the coast to breed, but in winter they retire into deeper water. The tope is viviparous, producing about 20 to 40 young in one season.

Through the kindness of Mr. T. E. Saunders, Collector of Fishery Statistics to the Board of Agriculture and Fisheries, I received some fresh livers, taken under his direction, from the freshly caught fish. There cannot, therefore, be any reasonable doubt as to the authenticity of the oil.

When finely minced and steamed, the livers yielded a considerable quantity of pale-coloured oil, having a rather strong, but not unpleasant odour. This gave on examination the following results:-

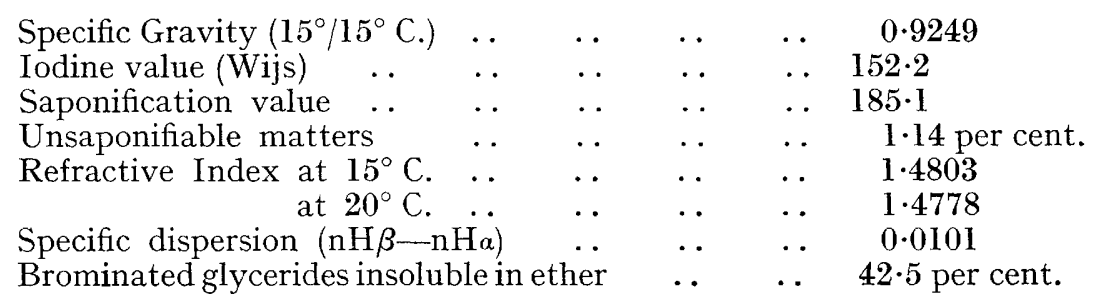

These numbers are, as will be seen, very similar to those given by cod-liver oil.

An interesting point is the high ether-insoluble bromide value. In shark liver oils containing large percentages of spinacene, the bromide value is very high indeed, but in the liver oils of fish belonging to the shark family, and which contain only relatively small proportions of unsaponifiable matters, the insoluble bromide value does not usually exceed 25 per cent.

I am informed that the oil is used for the dressing of leather, and that it is sometimes employed for medicinal purposes by the local fishermen. 
I do not know what medicinal or dietetic qualities this oil possesses, but in 1917 Dr. Drummond was good enough to make, at my request, an examination of the dog-fish liver oil, on which I was then working, and found that, as a source of the fat-soluble, growth-promoting accessory substance, it was equal to medicinal cod-liver oil. Probably tope liver oil would have a similar dietetic value. 